\section{(Clinical atotes:}

\section{MEDICAL, SURGICAL, OBSTETRICAL, AND THERAPEUTICAL.}

\author{
SUBMAXILLARY CALCULUS.
}

\section{By Colt.is BARRY, L.K.Q.C.P.I, M.R.C.S.}

THE following case is worthy of record on account of the unusual size of the caiculus and the gravity of the symptoms resulting from its presence.

R. W-- aged sixty-six, consulted me early in September last concerning a swelling beneath the lower jaw on the right side, which caused him extreme difficulty in swallowing. Flashing pains came on at intervals, and extended radially from the swelling upwards into the face and head, inwards towards the tongue, and downwards as far as the right shoulder and arm. These symptoms had existed for about eight months, becoming gradually more severe; latterly the patient had begun to lose flesh, and his friends became alarmed at his condition.

Upon examination I found a hard substance corresponding in position with the submaxillary gland placed just below the ramus of the inferior maxilla, rounded in form, and more easily distinguishable from the outer side than from the interior of the mouth, and about the size of a small walnut. By pressure from the outside a few drops of purulent discharge appeared at the orifice of Wharton's duct. There was no hardness or concretion at the mouth of the duct, as usually met with in cases of salivary calculus, and there was no induration of the cervical glands. Taking into consideration the gravity of the symptoms and the increasing loss of strength, I suggested early removal, but requested a consultation. Dr. Ainsley of Hartlepool saw the case with me and confirmed my suggestion. On Oct. 12th, chloroform being administered by Dr. Ainsley, I proceeded to cut down upon the submaxillary gland by a vertical incision about a quarter of an inch anterior to the facial artery as it crosses the inferior maxilla, extending downwards about two inches; a second cross incision was made to make room. There was considerable hæmorrhage from the submaxillary and other small branches of the facial. The whole of the gland superficial to the mylohyoid was removed, and the calculus could then be distinctly felt at the commencement of the duct, and apparently embedded in the gland. A few of the posterior fibres of the mylo-hyoid were divided, and the calculus seized with vulsellum forceps and removed. Upon examination after removal, the calculus proved to be phosphatic, and measured one inch by half an inch approximately (the exact measurement in length being uncertain, owing to the crumbling of a portion of the calculus beneath the vulsellum forceps). The wound was plugged with lint soaked in turpentine, eucalyptus ointment and iodoform being substituted upon the following day. The subsequent history of the case was one of uninterrupted recovery, the wound granulating freely and becoming entirely healed in three weeks from the date of operation, all the symptoms previously complained of having entirely disappeared.

Remarks. - The ordinary method of removal by incision of the mucous membrane was impracticable in this case owing to the depth of the calculus from the surface of the mucous membrane. Erichsen mentions, as the largest calculus removed, one of the size of a small damson-stone; but, so far as I can ascertain, no mention has been made of a calculus of this size occupying so deep a position.

Castle Eden, Durham.

\section{ERUPTIVE ECCENTRICITIES.}

\section{By J. G. Marshali, M.B.Cantab.}

Mrs. Q_- - aged forty-eight, married, living alone, had been a sufferer from chronic rheumatism for several years. She had an attack of facial erysipelas some time back, but could not fix the date. She was subject to occasional severe attacks of neuralgia, for which I could find no visible cause. About two months ago she presented the symptoms of erythema nodosum, and went through the illness in a severe and typical form, the patches being very large and painful, leaving the shins, back of forearms, and inside of thighs. covered with livid marks, as if she had undergone a beating At the end of a fortnight this eruption seemed to have run its course; but the patient still seemed very unwell, and complained of stiffness about the neck and jaws, with continual pain in the head. She maintained that she had been suffering from erysipelas, though she acknowledged that she had not been like it before. Two days after the last crop of erythematous lumps had disappeared she was seized with erysipelas of the head and face, and had it very severely, with high fever and extensive swelling of the face and neck,

She was for two or three days in a very critical condition, the features being almost obliterated, and the infiltration of the tissues of the neck deep and extensive. One morning when she was getting better she complained of intense itching of the back of the forearms and hands, which on examination presented the unmistakable white "wheals" of urticaria. There was little or no redness of the skin; the eruption was confined to the extensor surface, did not reach above the elbow, and died away in forty-eight hours. There had not been a trace of erysipelatous rash on the body during the attack of that disorder. A short time ago I congratulated her on getting on so well, when she said that she had another attack of erysipelas at the bend of the elbow. On examination of each elbow-joint, on the flexor side, and nowhere else, I found a patch of typical eczema, the vesicles being perfectly unmistakable, with watery exudation and shiny redness. She had been scratching with her nails, which she had not done before. Fresh patches of eruption appeared at the wrist. Both yielded readily to treatment, and now nothing is left but a little branny desquamation.

The case is such a remarkable one that $I$ think it deserves publication. I have not the smallest doubt as to the several characters of the eruptions, which I observed most carefully. Unfortunately I am at a disadvantage in being at a distance from any of my own profession, or I should have exhibited the case. I am quite prepared to see this lady shortly with a fine development of herpes zoster, or exhibiting patches of psoriasis to complete the series. She is of a highly nervoustemperament, and occasionally subject to fits of great excitability. St. Margaret's Bay, Dover.

\section{THE TREATMENT OF MALARIAL DISEASES BY} PICRATE OF AMMONIA.

By H. Martyn Clark, M.B., C.M. EdrN., IN CHARGE OF THE AMRITSAR MEDICAL MISSION.

Prcrate of ammonia possesses valuable therapentical properties, though it does not seem to have received the attention which it deserves. The characters, properties, and uses of this substance were carefully investigated by Dr. Dujardin-Beaumetz, and the results were communicated by him to the Therapeutical Society of Paris in 1872. ${ }^{1}$ The salt had previously been successfully used in the treatment of intermittent fever by Drs. Braconnot, Calvert, Aspland Bell, and others. Dr. Beaumetz's investigations contirmed the results at which these observers had arrived, and showed that in this substance we have a valuable, and efficient substitute for quinine in the treatment of malarial diseases. It appears to have passed out of mind, and, as far as I can gather, has never been used in India. My attention was directed to it accidentally in the following way. I had a patient under my care at a hill sanatorium who had suffered for seven months from severe intermittent fever of the quotidian type. Quinine, arsenic, and other antiperiodics had been, and were, freely used, but failed to give relief. After ten days' treatment the fever still recurred daily with its accustomed severity. At this juncture the local chemist told me of a remedy for fever, which he had received some years previously, but hed never tried. This I found to be picrate of ammonia. I gave it to my patient, with very gratifying results. The fever did not recur next day, nor did it do so at any time during the three subsequent months in which she remained under my observation. I have since then constantly used the picrate of ammonia in the treatment of malarial diseases. There lias been ample opportunity to test it fully, for Amritsar is notorious in the Punjab for its unhealthiness, and diseases of this kind are severe and frequent. During a period of four years and a half, I have treated over 
10,000 cases of these diseases with this agent, with the happiest results. So uniformly successful has it been that I have in our very extensive practice here, given up the use of quinine and the cinchona alkaloids for the treatment of intermittent fever, and have substituted picrate of ammonia for them. A record was kept of 5000 cases of intermittent fever treated with this agent. Of this number, in nine cases only did it fail to cure, and in these quinine succeeded at once. I usually give it in doses of from one-eighth of a grain to a grain and a half four or five times a day in pill. Half a grain is a fair average dose. Thus given the result is soon visible. In the great majority of the cases treated, half-grain doses in the interval prevented the recurrence of the next attack of the fever, while in about 20 per cent. of the patients two or three attacks followed before the fever ceased. In one case of quartan ague, despite large doses of the salt, the fever recurred for six periods, gradually diminishing in intensity, and then yielded to it. It is equally successful in all the forms of ague, but it is a curious fact that the cases in which it failed to cure were all of the tertian variety. I have also employed this agent in the treatment of twenty-five cases of malarial neuralgia of various nerves, six cases of malarial headache, and one of malarial colic. In all these instances it cured completely and speedily. In remittent fever it does not appear to be of use; six cases of a severe type were treated with it without any effect. Neither is the enlarged spleen of ague benefited by it. I have given it in numbers of such cases in conjunction with ergotine with good results, but such results are secured equally by the use of the ergotine alone.

My experience leads me to the conclusion that in all varieties of intermittent fever, and in malarial neuralgias, picrate of ammonia is a valuable antiperiodic, and it is an efficient and perfect substitute for quinia. It has the following advantages over quinine:- 1 . It is much less expensive. This is an important consideration where, as in Indian practice, hundreds of cases of malarial diseases have to be treated annually. 2. The dose given is very much smaller. 3. It does not produce the unpleasant effects that quinine does-headache, deafness, tinnitus, \&c.; nor does it disorder the digestion or cause nausea, as quinine is apt to do, in the doses in which it has to be given in India.

Amritsar, Punjab, Northern India.

\section{CASE OF TRAUMATIC TETANUS; RECOVERY.}

BY JoHN WeLPTON, L.R.C.P.L., M.R.C.S.

In The LANCET for 1886 two cases of recovery from tetanus (traumatic) are referred to. I had myself a short time ago a successful case.

On Sunday evening, Nov. 7th, I was called to B. B-, a tall powerful man about the age of thirty, and found him suffering from pronounced tetanus, with eyes fixed and staring, hands clasped behind the neck and quite rigid, and opisthotonus so strong that four people could with difficulty keep him down when the spasms were violent, those of the diaphragm being agonising. I placed him under the influence of chloroform, and administered within a short time two drachms of bromide of potassium, together with one drachm of chloral bydrate. I remained with him nearly three hours, when he became quieter and had no more spasms. He was quite well in two or three days. His friends did not know of any wound, but the man explained that in cutting a corn under the right great toe he had cut painfully into the quick three or four days ago. He was a night watchwan at that time and much exposed to the weather.

Ravensthorpe, Yorks

\section{CASE OF MELANOTIC SARCOMA.}

By J. N. BrEDIN, L.K.Q.C.P.I., \&c.

THE patient, a lady, aged fifty-four, first noticed a little spot on the right heel about the last week in October, 1886, thinking it was merely a chilblain or occasioned by a tight boot; it gradually, however, became troublesome, though entirely free from pain, and she then consulted my predecessor Mr. Holt, who advised a consultation. Accordingly, Mr. Rivington was called in, and advised an operation which was performed on Nov. $29 \mathrm{th}$, and seemed effectually to remove the mass. I saw the patient on Dec. 2nd. The growth had none of the characters whatever of melanosis-in fact, up to this time nothing showed itself from October to lead one to be certain. Meanwhile, Mr. Holt and Mr. Rivington suspected melanotic sarcoma. About eight days after the operation several spots of unmistakable melanosis appeared, first on the outside and subsequently on the inside of the thigh, and afterwards on the heel, and was now covering the cicatrix of the wound, which healed without intermission. All these places on the thigh and heel are now becoming confluent and extending and growing rapidly on the skin, without pain. One spot identical in character appeared on the head, and a single one on the back. Neither of these has increased in size, nor have any fresh ones appeared. This is, I presume, a most interesting and remarkable case, and may be seen by any medical man who may appoint an hour with me, as the patient is most willing to be seen by anyone.

Norton Folgate, E.C.

\section{g}

\section{HOSPITAL PRACTICE, BRITISH AND FOREIGN.}

Nulla autem est alia pro certo noscendi via, nisi quamplurimas et morborum et dissectionum historias, tum aliorum tum proprias collectas habere, et inter se comparare.-MoraAGNI De Sed. et Caus. Morb., lib. iv. Procmium.

\section{GUY'S HOSPITAL. \\ SEVEN CONSECUTIVE CASES OF CHARBON TREATED} SUCCESSFULLY BY EXCISION.

(Under the care of Mr. BRYANT.)

WE are able to publish a series of cases of malignant pustule which have occurred in the wards of Guy's Hospital during the course of the last few months, all of them under the care of one surgeon, and successfully treated in a similar manner, by excision, followed in some instances by the application of caustic. This disease is one of which during the last few years several examples have presented themselves in London, chiefly at Guy's and the London Hospitals, and much has been done by the surgeons of these institutions to advance our knowiedge of it. The cases, two of which we give this week, will be read with interest, and the difference in the local and constitutional symptoms carefully noted.

CASE 1.-Charbon of right temporal region, with lymphatic enlargement; excision; skin-grafting; cure. (From notes by Messrs. Du Boulay and F. P. Sarjant.)-Chas. Aaged twenty-nine, a labourer at a lide warehouse, was admitted on Jan. 21st, 1885. The patient's father died of aneurysm of the heart; his mother is living and well. He has been a hard worker, and steady in his habits. Had measles when a baby, and rheumatic fever when he was a boy (this lasted six weeks). About four years ago be was ruptured, and ever since has been wearing a truss. He has of late had some palpitation and nervousness. The patient, who works at a hide factory, was sent to the hospital by the manager (who, he thinks, had the disease himself some years ago). About Christmas last he came as an out-patient with a swelling like a boil on his left cheek. This was opened, and he got well. He was in his usual health up to Monday, the 19th ult., and was at his ordinary occupation, which consisted in handling hides of all kinds, which had come from all parts of the world; they were cow, ox, buffalo hides, and rabbit and opossum skine. While he was at work he felt an itching on his left temple, and putting up his hand felt a sinall pimple about the size of the head of a pin. He felt dull, depressed, and cold that day. On the Tuesday he still felt poorly, the pimple had increased to about the size of a pea, and the surface was black. On the Wednesday it was blacker and larger. During the whole time be had felt cold and unwell, but had kept at work until he was admitted into hospital.

Condition on admission.-The patient is a well-built, healthy-looking young man. When placed in bed he shivered and complained of bad headache. Temperature 